\title{
A Saga das Ciências Sociais na Área da Saúde Coletiva: elementos
}

para reflexão ${ }^{1}$

| 1 Maria Andréa Rios Loyola |

Resumo: O aporte das ciências sociais, a partir dos anos 1970, através de suas teorias e metodologias já consolidadas, foi indispensável para o desenvolvimento e consolidação da área que, no campo da saúde, se tornou conhecida como Saúde Coletiva. Em contraste com sua participação, as ciências sociais sempre ocuparam um lugar subalterno neste campo, dominado, em seus primórdios, isto é, durante as décadas de 1970 e 1980, pelo planejamento em saúde e, a partir da década de 1990, pela epidemiologia. O domínio da epidemiologia acontece justamente quando, reconhecida pela Capes como uma área autônoma, esperava-se maior equilíbrio entre as diferentes disciplinas que compõem a área da Saúde Coletiva. Este estudo levanta questões sobre a situação das ciências sociais na área, em relação com a execução da política de fomento das agências nacionais Capes e CNPq. A imposição de uma lógica custo-benefício de caráter predominantemente economicista e quantitativista, aplicada pelas agências na concessão de recursos, interfere tanto na produção quanto na circulação do conhecimento, com prejuízos para as ciências sociais. Contornar essa situação constitui um dos desafios que se colocam hoje para as ciências sociais e, em particular, para a área da Saúde Coletiva.

> Palavras-chave: Ciências sociais e saúde; periódicos em SAÚDE coletiva; produtividade e produtivismo em Saúde Coletiva; agências de fomento e Saúde Coletiva.
${ }^{1}$ Professora titular, Departamento de Políticas e Instituições de Saúde, IMSUERJ.

Endereço eletrônico: andrea.loyola@terra.com.br
Recebido em: 31/01/2008. Aprovado em: 14/04/2008 
Desde que as instituições de cunho mais acadêmico (de ensino e pesquisa), em saúde pública e medicina social começaram a se implantar no Brasil, as ciências sociais e humanas foram chamadas a prestar sua contribuição. $\mathrm{O}$ aporte destas ciências desde então, através de suas teorias e metodologias, foi indispensável para o desenvolvimento e consolidação da área que, no campo da saúde, se tornou conhecida como Saúde Coletiva. O próprio termo saúde coletiva evoca não apenas o estudo da saúde de uma coletividade, como a contribuição da coletividade em si mesma, enquanto sistema social, para o entendimento do que é saúde, como estado e como objeto de estudo.

Não obstante, a maior parte dos médicos, sempre ciosa da hegemonia que desfruta na área, nunca tenha deixado de pensar as ciências sociais como "disciplinas auxiliares" (o que, ainda hoje, coloca a saúde coletiva como segunda opção, senão a última, de boa parte dos cientistas sociais), alguns poucos profissionais dessas áreas perceberam ser este um campo privilegiado para pensar o social. E, como o foi, para fazer avançar o conhecimento da sociedade, da teoria e da metodologia em ciências sociais; como também para trazer à luz a importância de alguns temas ainda hoje tidos como "menos nobres" no próprio campo daquelas ciências. Para citar apenas um exemplo, o tema da sexualidade, e não apenas como prática responsável pela transmissão de certas doenças, mas no sentido foucaultiano, como lócus estratégico de controle social nas sociedades contemporâneas, fortemente medicalizadas.

Graças a esse esforço, vários e importantes estudos capitaneados ou influenciados pelas ciências sociais e pelas ciências humanas começaram a ser desenvolvidos: sobre a determinação social da doença, as instituições e as políticas de saúde, as relações entre indivíduo e sociedade, sobre os sistemas de saúde, as representações sociais da doença, sobre as práticas de saúde oficiais e alternativas, as diferentes racionalidades terapêuticas, a história das doenças e das epidemias, as profissões médicas, os movimentos sociais em saúde e tantos outros.

Em contraste com este formidável aporte, as ciências sociais da saúde sempre ocuparam um lugar subalterno em seu próprio campo e notadamente no campo da saúde coletiva. Por que isto acontece? Primeiramente, por uma perspectiva de classe fortemente impregnada na cultura ocidental: tudo que diz respeito ao social, em oposição ao individual (domínio da medicina nobre), tende a ser desvalorizado. Basta, para constatar isto, como sugere Bourdieu (2002), consultar o dicionário e 
observar as definições de social = coletivo, povo; $\mathrm{e}$ de individual = uno, único, etc. Em segundo lugar, pela hegemonia exercida pela medicina em tudo que diz respeito à saúde e, sobretudo, pela forma de construção desta hegemonia no campo da Saúde Coletiva, por definição um campo multidisciplinar. ${ }^{2}$

\section{O campo da Saúde Coletiva}

No período de formação e institucionalização, o campo da Saúde Coletiva foi dominado principalmente pelos profissionais (com exceção de alguns cientistas sociais que se destacaram no período), a maioria médicos, que num contexto como o dos anos 70 e 80, ao mesmo tempo extremamente politizado e politicamente reprimido, fizeram da saúde pública um instrumento político de transformação social. Esses profissionais estiveram na liderança do movimento sanitarista que culminou com a criação do SUS e com o reconhecimento da saúde como um direito universal consagrado na Constituição de 1988, movimento que, como mostra Nunes (2005), esteve intrinsecamente ligado à formação do campo da Saúde Coletiva. Esses atores estavam voltados, sobretudo, para as tarefas de aprimoramento do Estado enquanto promotor e provedor da saúde no país, como reza aquela Carta Magna. O planejamento e a administração em saúde dominaram o campo da Saúde Coletiva praticamente até a década de 1990.

Com a democratização do país e o relativo esgotamento desse projeto político, sem dúvida bem-sucedido (muitos professores e pesquisadores passaram a exercer atividades ou a terem postos e funções diretamente nas instituiçôes políticas e estatais, nacionais e internacionais), os planejadores e administradores de saúde, agora atuando no interior do próprio Estado, gradativamente perderam importância na dimensão acadêmica do campo, abrindo espaço para novos profissionais, notadamente para os epidemiólogos.

$\mathrm{Na}$ ausência de um projeto político coletivo, capaz de aglutinar em uma só direção os esforços do conjunto de profissionais e de disciplinas que compõem a área, esta foi aos poucos se burocratizando e "disciplinarizando-se", ou seja, fechandose em torno das diferentes disciplinas que compõem o campo nas suas principais áreas de concentração: Epidemiologia, Planejamento e Ciências Humanas. 


\section{A Saúde Coletiva e o desenvolvimento da pesquisa no país}

O rápido desenvolvimento da pesquisa ocorrido a partir dos anos 1980, que se deu associado ao crescimento dos cursos de pós-graduação e, desta forma, concentrado nas universidades públicas, agravou consideravelmente esta situação. De fato, a prioridade conferida às linhas de pesquisa, em detrimento dos departamentos e das instituiçôes em seu conjunto, não raramente tem levado, para além de uma forte especialização, a uma verdadeira atomização e autonomização do conhecimento produzido pelos pesquisadores da área. Isso se faz sentir também no ensino, que passa a ser ministrado em função dos interesses dos pesquisadores e de seus projetos de pesquisa, levando a um empobrecimento, para não dizer a uma quase perda do sentido e da concepção original de Saúde Coletiva.

Esses processos de atomização e autonomização, com tendência a se radicalizarem em algumas instituições da área, se manifestam na multiplicação de siglas distintivas de grupos dentro de uma mesma instituição e de um mesmo departamento. Siglas que passam a funcionar como principal elemento identificador de grupos, como pode ser facilmente observável nos créditos das atividades, publicações etc. de seus membros, onde a sigla das instituiçôes geralmente consta em segundo lugar, ou às vezes nem aparece. Além de marketing, essas siglas são utilizadas como instrumento de captação e distribuição de recursos, em geral privados (para pesquisa, publicações, condições de trabalho, realizações de eventos, pró-labore, bolsas, etc.), o que, face ao progressivo sucateamento das universidades públicas, vem levando à formação de verdadeiros feudos em algumas dessas instituiçôes, apontando para um perverso e silencioso processo de privatização das universidades públicas.

$\mathrm{Na}$ ausência de um projeto político mais amplo, aumentar o conceito dos cursos junto à Capes (e por conseqüência dos recursos a ele atrelados) vem-se constituindo na principal bandeira das instituiçôes, no principal elemento aglutinador da vontade daqueles grupos - em muitas delas, num verdadeiro projeto institucional. Na prática, entretanto, a perseguição deste fim vem-se tornando mais um fator de desagregação, reforçando e ampliando as tradicionais contradiçôes e a complexidade da área de Saúde Coletiva, principalmente entre a área predominantemente médica, como a epidemiologia, e as áreas das ciências humanas e sociais e do planejamento. 


\section{O papel das agências de fomento}

As agências governamentais de fomento, notadamente Capes e CNPq, tiveram e têm um papel fundamental nesse processo: menos por sua política global, cuja contribuição para o desenvolvimento da pesquisa e da pós-graduação no país é inegável, mas pela forma com que os efeitos desta política vêm sendo assimilados e administrados, em certas áreas, no interior de grande parte das instituições de ensino superior do país. E aqui é necessário falar um pouco, ainda que rapidamente, da maneira como essas agências contribuíram para o processo mais amplo, descrito por Luz (2005), relativamente à Saúde Coletiva, de hierarquização das principais atividades universitárias: sobrevalorização da pesquisa em detrimento do ensino; sobrevalorização da pós-graduação em detrimento da graduação.

Como é sabido, embora consideradas agências irmãs, Capes e CNPq têm origens, finalidades e trajetórias diferentes. A Capes foi criada, como o nome indica (Coordenação de Aperfeiçoamento do Pessoal de Nível Superior) com o objetivo de aprimorar a qualificação dos docentes das universidades. O CNPq, também como o nome indica (Conselho Nacional de Pesquisa e, atualmente, de Desenvolvimento Científico e Tecnológico), teve e tem como objetivo o desenvolvimento da pesquisa e a formação de pesquisadores capazes de promover o desenvolvimento tecnológico do país. A Capes sempre trabalhou com as instituições (através das sub-reitorias de pós-graduação); o CNPq, com os indivíduos, os pesquisadores. A Capes sempre se preocupou com a qualidade do ensino; o CNPq, em formar uma elite de pesquisadores. A Capes sempre foi dirigida por educadores ou profissionais voltados para a educação, sendo que seus três últimos presidentes, antes do atual, eram cientistas sociais - entre estes, duas mulheres. $\mathrm{O} C N P q$, desde seu início, tem sido dirigido por representantes das ciências exatas ou biológicas (quadros 1 e 2). A Capes sempre teve uma burocracia reduzida, formada majoritariamente por mulheres; o CNPq, uma extensa burocracia e majoritariamente homens ocupam postos de comando. 
Quadro 1: Área de atuação dos presidentes da CAPES 1990-2007

\begin{tabular}{|l|l|}
\hline \multicolumn{1}{|c|}{ Nome } & \multicolumn{1}{c|}{ Área } \\
\hline Eunice Ribeiro Durham & Antropologia \\
\hline Sandoval Carneiro Júnior & Engenharia \\
\hline Maria Andréa Loyola & Sociologia/Antropologia \\
\hline Abílio Afonso Baeta Neves & Ciência Política \\
\hline Carlos Roberto Jamil Cury & Educação \\
\hline Marcel Bursztyn & Economia \\
\hline Jorge Almeida Guimarães & Bioquímica \\
\hline
\end{tabular}

Fonte: Capes.

Quadro 2: Área de atuação dos presidentes do CNPq 1990-2007

\begin{tabular}{|l|l|}
\hline \multicolumn{1}{|c|}{ Nome } & \multicolumn{1}{c|}{ Área } \\
\hline Gerhard Jacob & Física \\
\hline Marcos Luís dos Mares Guia & Bioquímica \\
\hline Lindolpho de Carvalho Dias & Matemática/Engenharia \\
\hline José Galizia Tundisi & Ciências/Ecologia \\
\hline Evando Mirra de Paula e Silva & Engenharia \\
\hline Esper Abrão Cavalheiro & Medicina/Fisiologia \\
\hline $\begin{array}{l}\text { Erney Felício Plessmann } \\
\text { Camargo }\end{array}$ & Parasitologia \\
\hline
\end{tabular}

Fonte: CNPq.

Quando assumi a presidência da Capes, no final de 1992, o sistema de avaliação dos cursos era ainda efetuado pelo recorte por letras - A, B, C, D e E-, encontrandose a maioria dos cursos, pelo menos os do Sudeste, nas duas primeiras categorias. 
Havia, na época, uma forte insatisfação com esses critérios, considerados pouco discriminatórios. Foram então convocados pela Capes os coordenadores e outros especialistas das diferentes áreas para promoverem uma revisão dos critérios vigentes e traçarem o que ficou conhecido como o "perfil dos cursos A", ou seja, o conjunto de princípios e exigências necessários para que um curso fosse considerado $A$, no geral e por área. O objetivo dessa revisão era garantir o máximo de referências para o aprimoramento da qualidade dos cursos, respeitando as especificidades de cada um e de cada região. Vale lembrar que uma das principais características de nosso sistema universitário, aí incluída a pós-graduação, é sua heterogeneidade: tanto entre as áreas do conhecimento, como entre as regiōes, entre as instituições de uma mesma região e os diferentes cursos de uma mesma instituição.

No perfil de curso A, "a produção acadêmica docente: deve valorizar a qualidade e a efetiva contribuição que a produção científica possa representar para cada área, mais do que a quantidade de artigos e de livros produzidos" (MEC, 1994). Sugeria-se também a integração, mesmo que indireta, com a graduação e o acompanhamento dos egressos para verificar se o curso estava de fato cumprindo seus objetivos ou apenas formando profissionais subutilizados, com desvio de função ou simplesmente desempregados. Acima do conceito A, vinha o conceito de "excelência", estabelecido por solicitação do próprio curso, e cujo processo de avaliação contaria com a participação de especialistas internacionais.

Esta proposta, salvo engano, não chegou a ser testada porque, pouco depois, logo no início do governo Fernando Henrique, guardando alguns princípios já estabelecidos, esse sistema foi substituído pelo sistema numérico que conhecemos hoje. A própria informatização da Capes, iniciada em 1993, induziu uma crescente burocratização do órgão e favoreceu a tendência quantitativista já praticada pelo $\mathrm{CNPq}$, que pouco a pouco foi transferindo para aquele órgão sua "cultura” forjada segundo o modelo das ciências "exatas" e biológicas. Isso culmina com a adoção da plataforma Lattes, que, pelas vantagens que introduz uniformização, transparência e informação ágil e de fácil accesso - foi eleito como medida nacional de produtividade e de hierarquização de docentes e pesquisadores e como caminho incontornável na distribuição de recursos. Produtividade sintetizada em números de produtos, ao final deste currículo, que se tornou uma espécie de "selo de qualidade" dos pesquisadores. 


\section{$\mathrm{O}$ produtivismo científico ou a ciência em números}

Este produtivismo estimulado e modelado pela globalização ou internacionalização do conhecimento, levado a cabo por uma burocracia estatal desejosa de garantir critérios objetivos e democráticos para a avaliação de mérito, mas também (de forma menos consciente ou explícita) de controlar o trabalho dos cientistas e de limitar sua autonomia - vale notar, com a cumplicidade dos próprios cientistas -, produz também efeitos perversos, como os descritos por Luz (2005), sobre o nosso tempo, nossa capacidade de pensar, nossa saúde, em suma, sobre nossa vida profissional e pessoal. E, naturalmente, sobre as exigências metodológicas, a qualidade e a integridade dos trabalhos. Numa verdadeira "multiplicação dos pães", estes são recortados, requentados e apresentados a diferentes periódicos e veículos de circulação. E nessa corrida ganham sempre os mais espertos, os mais articulados e com maior capacidade de exercer pressão sobre os editores. No caso do livro, aqueles com recursos para bancar, em parte ou na totalidade, sua edição. Nas ciências sociais isto tem produzido o que Ana Reis, uma acadêmica feminista, chama de "fast social sciences": trabalhos rapidamente fabricados, facilmente reconhecíveis e rapidamente consumíveis.

O astro (talvez fosse melhor dizer o carrasco) deste sistema é o computador: quem hoje não for profundamente informatizado (e isto significa não só saber manusear com maestria um computador, como principalmente pensar informaticamente, ou seja, de forma pré-formatada) não pode ser cientista, pelo menos um cientista de sucesso, aqui e no resto do mundo. Claro que existem justificativas para esse sistema: reais, mas não suficientes para explicá-lo, como o crescimento dos cursos de pós-graduação, do número de pesquisadores (relativamente aos recursos governamentais disponíveis), da própria produção científica (em sua maior parte estimulada por este sistema) e, o mais curioso: a garantia de qualidade e a busca da excelência.

\section{A (re)produção e a circulação do conhecimento em Saúde Coletiva}

Soma-se à sobreposição da lógica de pesquisa e das linhas de pesquisa sobre o ensino e o projeto institucional, outra transformação importante trazida pela invasão do mercado na vida universitária, e talvez a mais nefasta: a substituição da forma 
ou dos modos de produção, pelo modo de circulação do conhecimento - também aceita sem críticas pelos professores/pesquisadores, principalmente pelos mais jovens, ansiosos por reconhecimento e por impulsionarem suas carreiras. Não é mais o conteúdo, a originalidade e a contribuição, mas o veículo e os índices de impacto que determinam a qualidade do produto e o mérito de seu autor. $\mathrm{O}$ ano 2000 já se inicia sob a égide da indexação e prossegue sob aquela dos Qualis, aprofundando o enquadramento e a formatação do pensamento, de sua expressão e conteúdo pelas regras de circulação.

Atributos essenciais do modo de produção do trabalho intelectual, como autonomia e tempo, são sacrificados em nome de uma circulação rápida, do texto sintético e de preferência em inglês. (E aqui um parêntese para comentar a imposição colonialista desta língua docilmente aceita pela maioria em nome de "serem lidos", esquecendo-se, além dos custos em esforço e dinheiro que isto requer, que por melhor que seja o nosso inglês ou aquele dos nossos tradutores, jamais poderemos competir em condiçôes de igualdade com aqueles que pensam nessa língua e que dispõem das condiçôes de trabalho próprias àqueles países que a falam. E é claro que estou me referindo a países como Inglaterra e principalmente EUA, e não à África do Sul).

Transferem-se assim, para os editores, as decisões (em primeira e em última instância) sobre o que e como publicar e naturalmente que o custo da edição e seu retorno - a comercialização - acabam sobrepondo-se a quaisquer outras considerações. Mesmo nas publicações subvencionadas, é a circulação, ou seja, o impacto, quantitativamente mensurado, que determina as estratégias editoriais. Por tudo isso é que o livro (dispendioso em tempo e dinheiro, tanto para o leitor como para o editor) começa a sofrer várias restrições, muitas vezes pelos próprios autores e leitores que poderiam dele se beneficiar. Sob essa lógica, o livro, tradicional transmissor de cultura, estilo e pensamento (porém mais difícil de ser internacionalizado), não tem lugar, situação recentemente revertida pela Diretoria de Avaliação da Capes, para as áreas em que ele é considerado importante: entre estas, as ciências sociais e humanas. Além disso, são levadas em conta apenas as produções mais recentes - os últimos cinco ou três anos - o que, se por um lado abre espaço para os jovens, por outro induz ao esquecimento a produção cumulativa da área como um todo e, por via de conseqüência, sua memória.

Estas considerações, no geral, são válidas para todas as áreas e a maior parte delas tem conseguido ajustar seus critérios de avaliação à sua produção e vice- 
versa, aparentemente sem muitos problemas. Em parte porque a ênfase conferida ao tipo de exigência, ao número de artigos e a escolha dos periódicos, é dada principalmente pela área e não pela agência que, no geral, tem-se revelado relativamente bem mais flexível. Problemas e dificuldades maiores passam a existir, de forma crescente, nas áreas multidisciplinares e de forma especial naquelas que conjugam ciências médicas/biológicas e ciências humanas e sociais, como é o caso da Saúde Coletiva, uma vez que são aquelas ciências que vêm levando ao paroxismo esse produtivismo.

Paralelamente às críticas que se multiplicam, sobre nossa incapacidade de transformar conhecimento em valor, inovação em patentes, na sessão de ciência de $O$ Globo do dia 10/07/2007, o Prof. Jorge Guimarães, Presidente da Capes, informa, com justa razão, orgulhoso, que o Brasil alcançou a $15^{a}$ posição no ranking Thompson ISI, ultrapassando a Suíça e a Suécia. De fato, o número de artigos publicados em 2006 cresceu em 33\% em relação a 2004, e o maior crescimento relativo foi da medicina, $47 \%$. Naturalmente que nesse ranking os Estados Unidos ocupam o primeiro lugar, com 32,30\%; mas Alemanha e Japão, segundo e terceiro colocados, comparecem com $8,10 \%$ e $8,8 \%$. Todos os demais países apresentam scores inferiores a $8 \%$.

Para a Saúde Coletiva, essa verdadeira obsessão pela quantidade de produtos indexados trouxe um descompasso profundamente desagregador, porque permitiu o aparecimento de critérios de avaliação de pesquisadores e de cursos que favorecem fortemente uns e excluem, também fortemente, outros, prometendo uma batalha que já se manifesta na área e na qual, se alguns podem sair mortos, todos certamente sairão feridos.

\section{Os periódicos de Saúde Coletiva e seus (im)pactos}

Os periódicos de Saúde Coletiva com maior fator de impacto no sistema Scielo são (BARROS, 2006), de um lado, os Cadernos e a Revista de Saúde Pública (ambos classificados como Qualis A internacional), e de outro, a revista da Abrasco, Ciência \& Saúde Coletiva (Qualis C internacional), multidisciplinar por nascimento e especialmente criada para acolher as variadas publicaçôes da área, notadamente as de ciências sociais, e para funcionar como contraponto às publicações de orientação mais próxima à da medicina. 
O número de artigos publicados nesses periódicos varia segundo a inserção institucional do autor principal e tendem a se concentrar nas instituições maiores e mais tradicionais da área, à quais os periódicos e seus editores também pertencem: Cadernos de Saúde Pública e Revista Ciência \& Saúde Coletiva, na ENSP/Fiocruz; Revista de Saúde Pública, na USP (quadros 3, 4 e 5) e, conseqüentemente, nos estados onde elas se localizam: Rio de Janeiro e São Paulo. No geral, essa concentração regional espelha o desequilíbrio entre as regiōes do país, gerado pelo sistema "bola de neve" que vigora em nosso sistema nacional de pós-graduação, que favorece as instituições mais avançadas, com maior número de doutores e tecnicamente mais bem equipadas.

\section{Quadro 3: Distribuição dos artigos dos Cadernos de Saúde Pública por} vinculação institucional do autor principal - 2005/2006

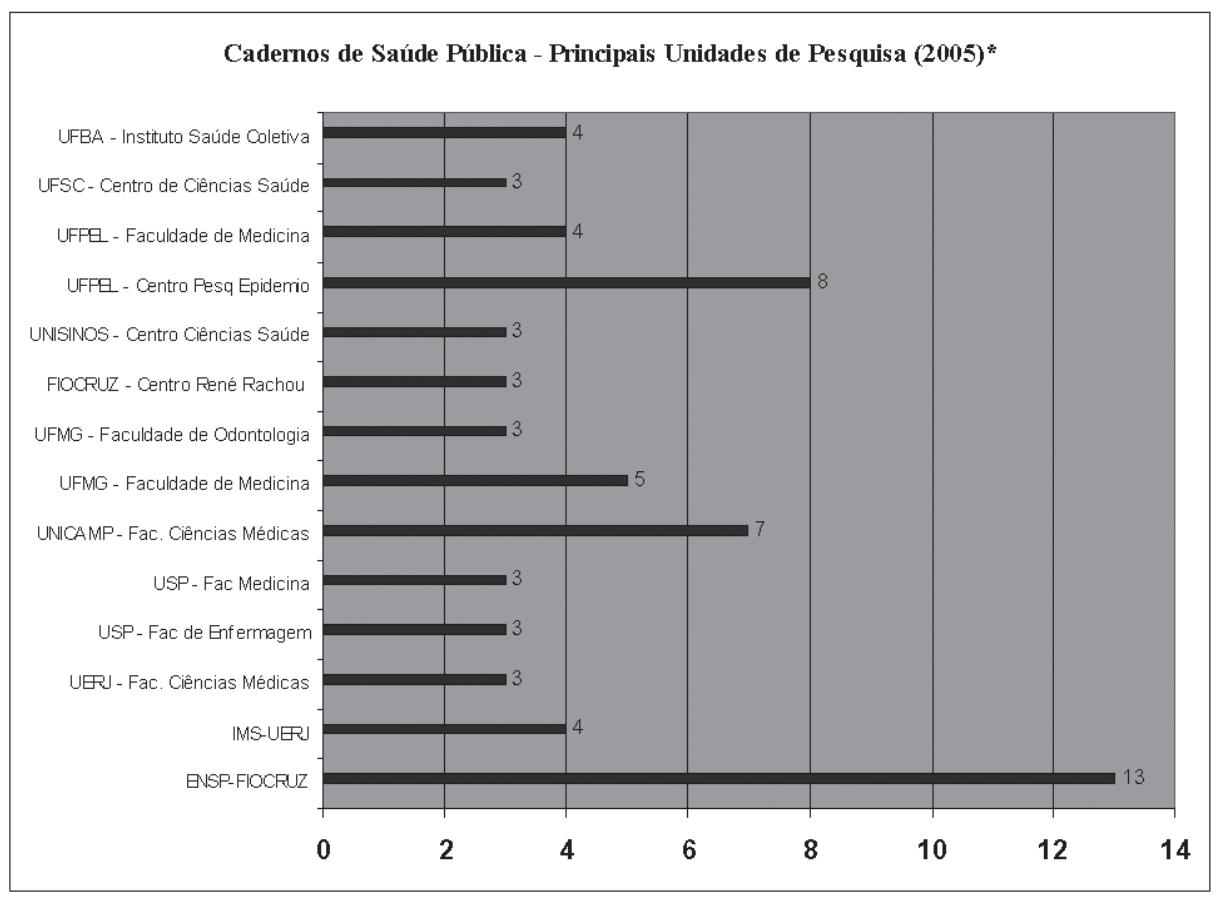


Cadernos de Saúde Pública - Principais Unidades de Pesquis a (2006)*

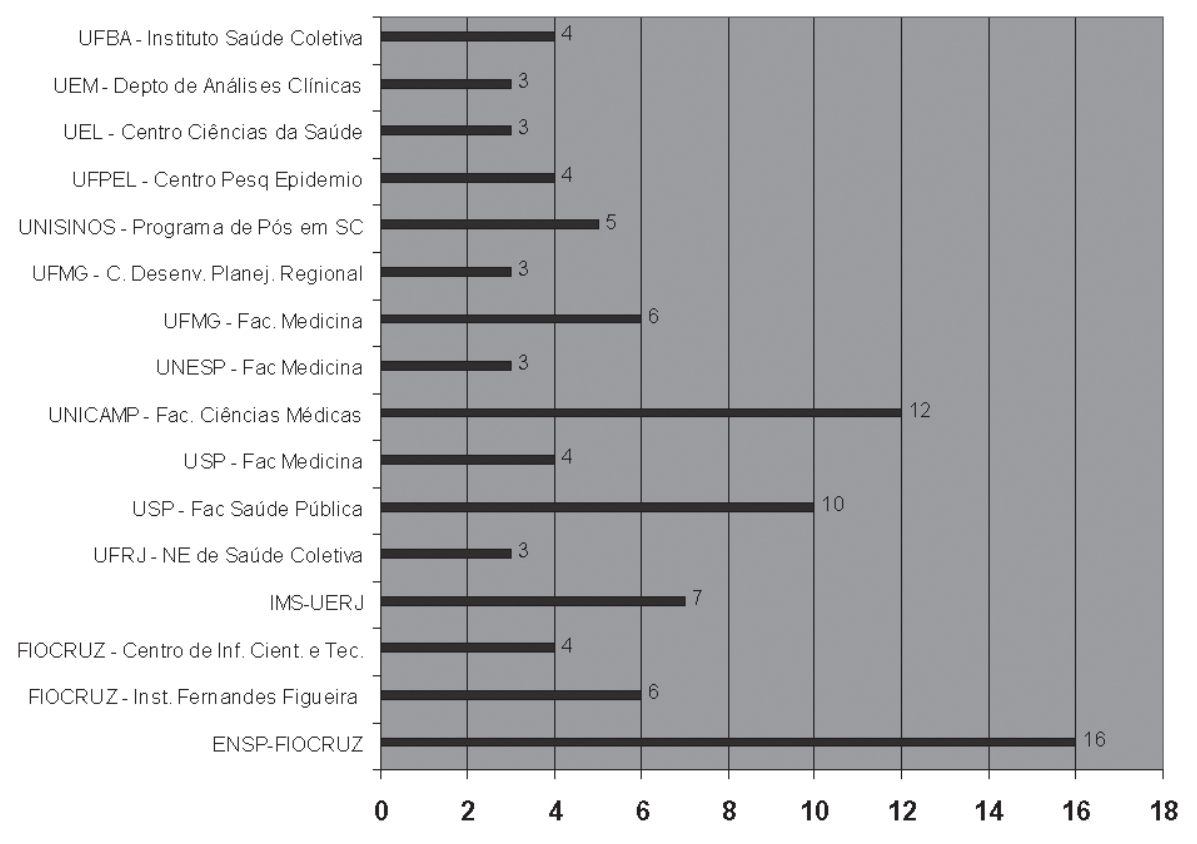

*Foram excluídas as unidades que apresentaram menos de três artigos/ano. Fonte: Cadernos de Saúde Pública.

\section{Quadro 4: Distribuição dos artigos da Revista Ciência \& Saúde Coletiva} por vinculação institucional do autor principal - 2005/2006

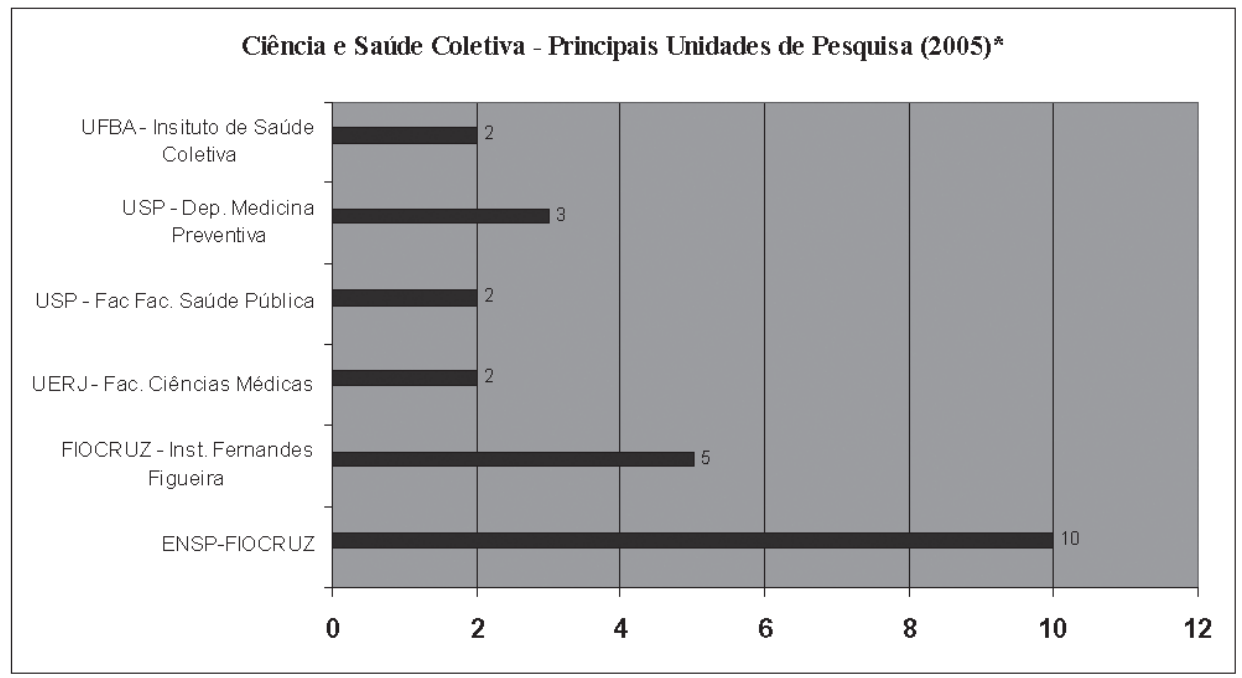




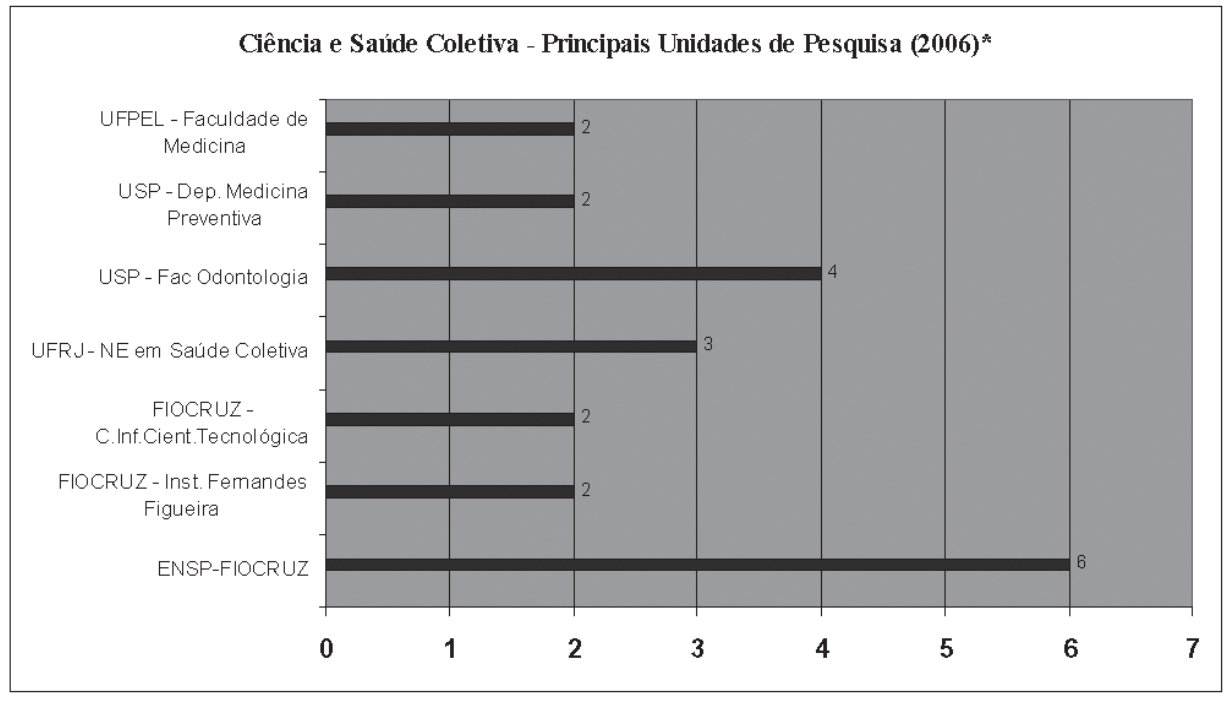

*Foram excluídas as unidades que apresentaram menos de um artigo/ano. Fonte: Revista Ciência e Saúde Coletiva.

Quadro 5: Distribuição dos artigos da Revista de Saúde Pública por vinculação institucional do autor principal - 2005/2006

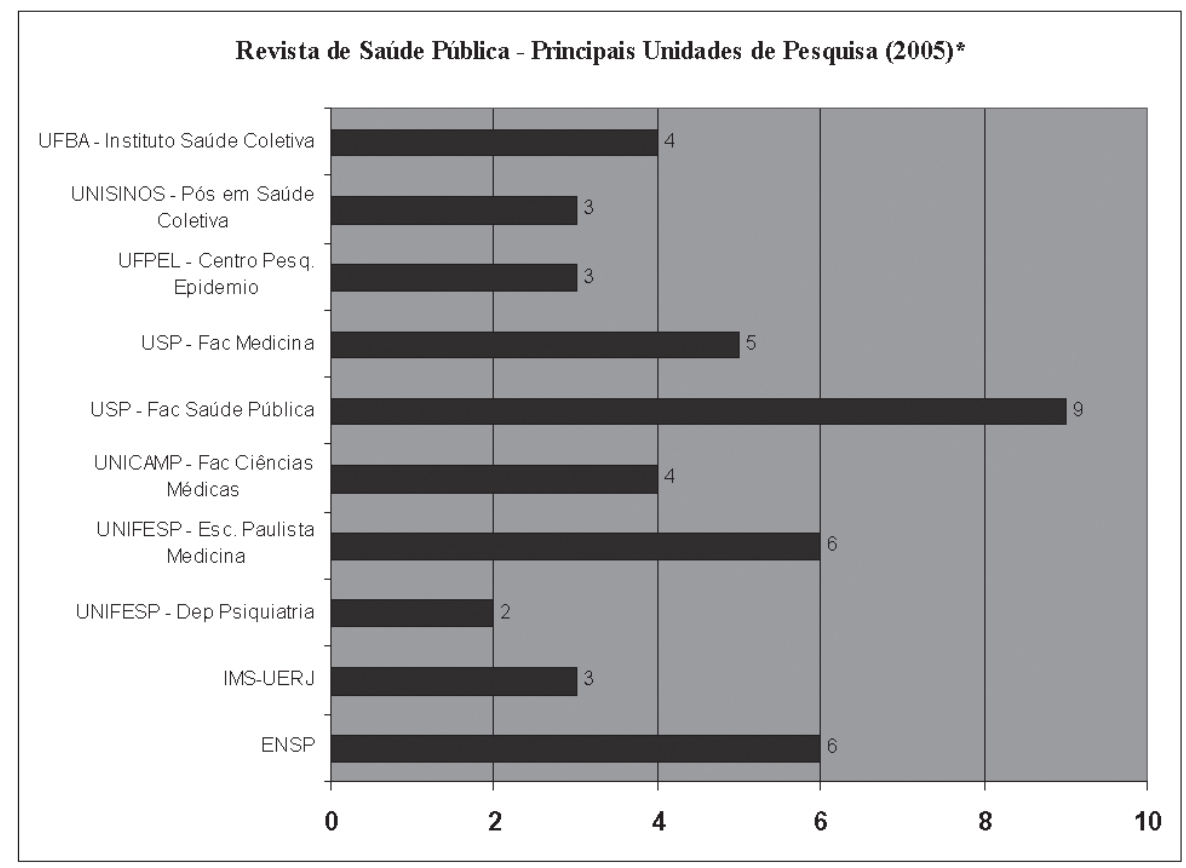




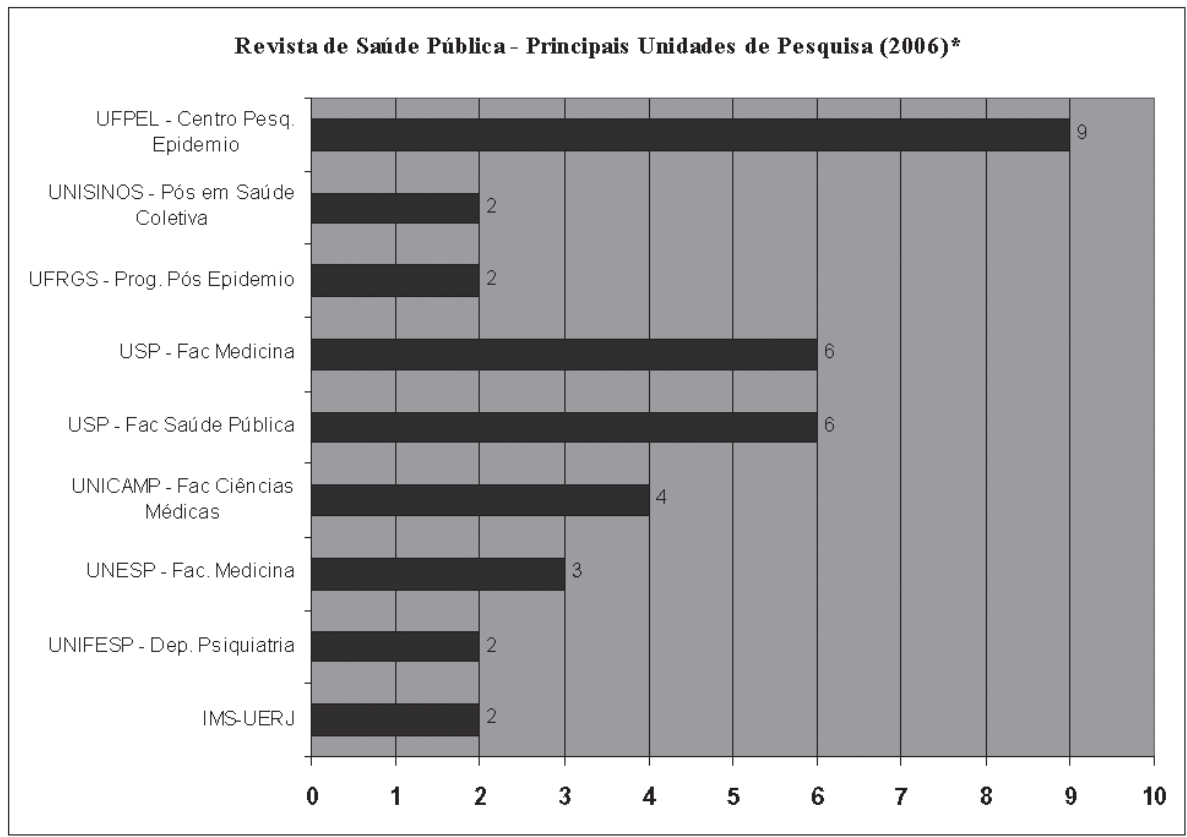

*Foram excluídas as unidades que apresentaram menos de um artigo/ano. Fonte: Revista de Saúde Pública.

Se examinarmos a distribuição, nesses periódicos (gráfico 6), dos artigos por subáreas da Saúde Coletiva (apêndice metodológico, anexo 1), podemos observar que o ano de 2005 apresenta uma larga predominância de artigos de epidemiologia tanto nos Cadernos (49,1\%) como principalmente na Revista de Saúde Pública (57,5\%). Na Ciência \& Saúde Coletiva, como era de se esperar, a situação se inverte: as ciências sociais e humanas, seguidas do planejamento, apresentam os maiores percentuais de artigos publicados $(36,8 \%$ e 28,3\%, respectivamente, contra 20,8\% da epidemiologia) e, de um modo geral, existe, nessa revista, maior equilíbrio entre as três áreas. Entretanto, se observarmos a distribuição relativa ao ano de 2006 (gráfico 7), constatamos que o número de artigos da epidemiologia cresce em todas essas publicações e, notadamente, na Ciência e Saúde Coletiva, passando de 20,8\%, em 2005, para 32,7\%, em 2006 (mais 12\%) - o que acontece em detrimento apenas das ciências humanas e sociais, que diminuem seu peso em 15\%, ou seja, passam de 35,8\%, em 2005, para apenas 20\% em 2006. 
Gráfico 6: Distribuição dos artigos nos periódicos Cadernos de Saúde Pública; Revista de Saúde Pública e Ciência \& Saúde Coletiva, por área, em 2005
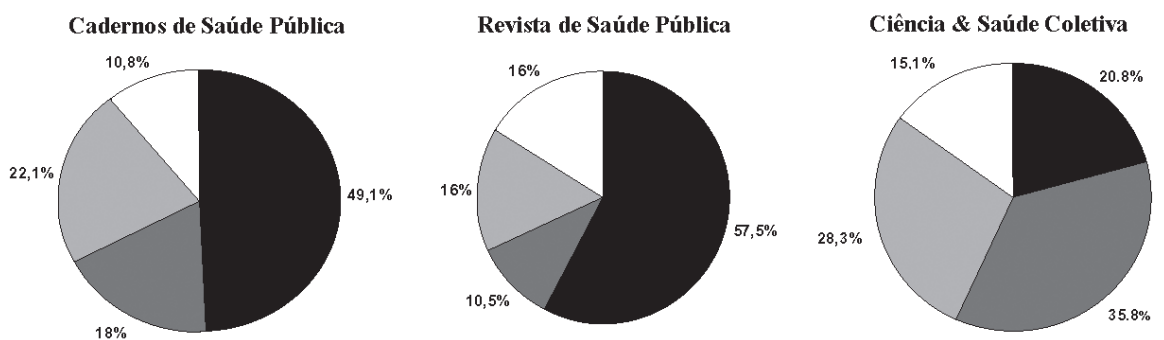

Epidemiologia $\square$ Ciências Humanas $\square$ Política e Planejamento $\square$ Diversas

Fonte: Cadernos de Saúde Pública, Revista Ciência \& Saúde Coletiva, Revista de Saúde Pública.

Gráfico 7: Distribuição dos artigos nos periódicos Cadernos de Saúde Pública, Revista de Saúde Pública e Revista Ciência \& Saúde Coletiva, por área, em 2006

Cadernos de Saúde Pública

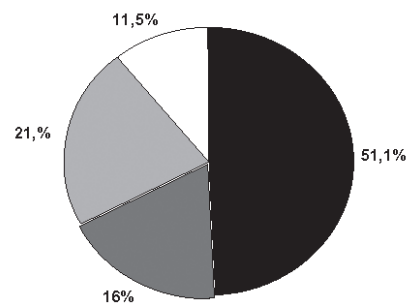

Revista de Saúde Pública

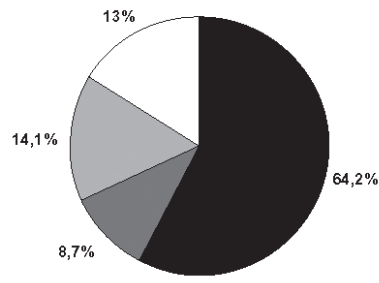

Ciência \& Saúde Coletiva

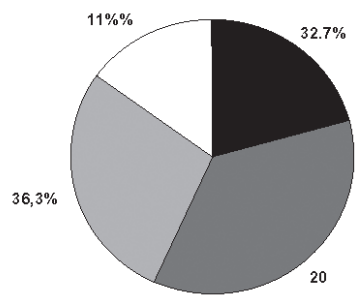

Epidemiologia $\square$ Ciências Humanas $\square$ Política e Planejamento $\square$ Diversas

Fonte: Cadernos de Saúde Pública, Revista Ciência \& Saúde Coletiva, Revista de Saúde Pública.

O gráfico seguinte (gráfico 8) apresenta a distribuição dos editores dessas revistas segundo as três subáreas consideradas, mostrando que existe forte correlação entre a área dos editores e aquela dos artigos: nos Cadernos e na Revista dominam os epidemiólogos, e na Ciência \& Saúde Coletiva mantém-se um relativo equilíbrio, com destaque para o planejamento, o que pode explicar o aumento dos artigos dessa área. 

e Revista Ciência \& Saúde Coletiva por área de atuação dos membros dos seus conselhos editoriais - 2005/2006
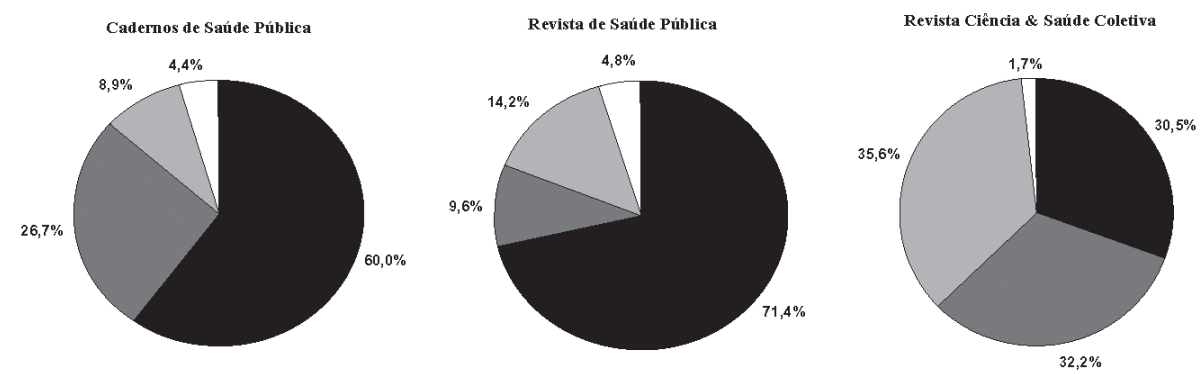

Epidemiologia $\square$ Ciências Humanas $\square$ Política e Planejamento $\square$ Diversas

Fonte: Cadernos de Saúde Pública, Revista Ciência \& Saúde Coletiva, Revista de Saúde Pública.

Se é a demanda, ou seja, a quantidade de artigos enviados para publicação que determina a escolha dos editores ou o contrário, pouco importa: os epidemiólogos reinam soberanos nesses espaços. E não por acaso, reinam também entre os bolsistas de produtividade do CNPq, como mostram Barata e Goldbaum (2003), que registram também preocupação com esse desequilíbrio.

Segundo todos esses dados, os epidemiólogos são os pesquisadores mais produtivos da Saúde Coletiva e não tenho dúvidas de que eles o são de fato, por mérito e direito. Mas isso quer dizer que as demais áreas que compõem a Saúde Coletiva são menos produtivas?

Mesmo sem entrar no mérito dos artigos, até prova em contrário, eu diria que não. Os epidemiólogos são quantitativamente mais produtivos porque os veículos de divulgação mais bem classificados no sistema Qualis e que servem de medida de produtividade dos pesquisadores e dos cursos de pós-graduação estabelecem normas de publicação que se coadunam com o modo de produção da epidemiologia: uso de bases estatísticas e de softwares que agilizam a obtenção de resultados, exigência limitada de discussão teórica, etc. Tais normas, como o número cada vez mais limitado de páginas, abolição das notas de rodapé, essenciais para reforçar e localizar a argumentação nas ciências humanas, acaba por empobrecer, mutilar e mesmo inviabilizar a publicação de artigos nessa área. Isso aparece também na média do número de autores dos artigos das revistas analisadas (quadro 9), que 
têm efeitos multiplicadores para os índices de impacto e começam a ser imitados, com conseqüências ainda não avaliadas, pelos cientistas sociais.

Quadro 9: Número médio de autores por artigo publicado, por área (nos periódicos considerados)

\begin{tabular}{|l|c|c|c|}
\hline \multirow{2}{*}{\multicolumn{1}{|c|}{ Área }} & \multicolumn{3}{c|}{ Número médio de autores } \\
\cline { 2 - 4 } & CSP & Rev SP & C\&SC \\
\hline Epidemiologia & 4,3 & 4 & 3,9 \\
\hline $\begin{array}{l}\text { Ciências Sociais e } \\
\text { Humanas }\end{array}$ & 2,4 & 2,4 & 2 \\
\hline Política/Planejamento & 2,7 & 4 & 3,6 \\
\hline Diversos & 4,3 & 3,7 & 2,6 \\
\hline
\end{tabular}

Fonte: Cadernos de Saúde Pública, Revista Ciência \& Saúde Coletiva, Revista de Saúde Pública.

Paralelamente ao incentivo à corrida aos periódicos indexados, promoveu-se o desestímulo a produção de livro e de capítulos de livros na área, limitando sua participação, no conjunto da produção docente de cada curso, a 30\%. E, recentemente, sob o pretexto de ser difícil avaliá-los, decidiu-se também, à maneira dos periódicos, trocar o conteúdo pelo veículo de difusão, lançando um novo Qualis, o Qualis-livro, ou melhor, Qualis-editora. De fato, em reunião realizada em março de 2007, o Fórum de Coordenadores de Cursos de Pós-Graduação classificou como Qualis A internacional várias editoras internacionais (todas de língua inglesa) pelo critério de maior circulação, e apenas sete nacionais, pelo critério dominante de "haver publicado seis ou mais livros da área no último triênio". Entre as editoras selecionadas não figuram as principais editoras universitárias, mas estão presentes algumas editoras cujo critério de publicação é eminentemente comercial. Em função desse "Qualis livro", pertinentemente criticado por docentes da USP (2007), muitos dos professores mais experientes e comprometidos com a área, que publicaram livros por editoras excluídas ou não consideradas nessa seleção, estão hoje rebaixados a "docentes de segunda classe" e impedidos de orientar teses. 


\section{O domínio da epidemiologia}

Minha preocupação com os critérios de avaliação dos cursos de pós-graduação me levou, ainda no final de 1992, não sem fortes reações e com muita costura política, a desvincular a área da saúde coletiva da área médica, transformando-a numa área autônoma. Imaginava que isto permitiria que os cursos de Saúde Coletiva fossem avaliados segundo critérios estabelecidos pelos pares desta área e não pelos médicos (em sua maioria clínicos), como vinha ocorrendo.

O que aconteceu a partir daí ou como foi a participação das diferentes disciplinas na representação da área, cujo titular tem assento no Conselho Técnico-Científico, que discute a política do órgão e dirige todo o processo de avaliação dos cursos e das demandas por fomento (bolsas, participação e organização de eventos etc.), indicando inclusive o nome dos avaliadores? A resposta a esta questão se encontra no gráfico sobre os representantes de área na Capes, nos últimos 12 anos (quadro 10).

Quadro 10: Representantes da área de Saúde Coletiva da CAPES por formação (1993-2007)

\begin{tabular}{|l|c|}
\hline \multicolumn{1}{|c|}{ Área } & N. \\
\hline Epidemiologia & 3 \\
\hline Ciências Humanas & 1 \\
\hline $\begin{array}{l}\text { Política e Planejamento em } \\
\text { Saúde }\end{array}$ & 0 \\
\hline Diversas & 0 \\
\hline
\end{tabular}

Fonte: Capes. 
Ele nos mostra que desde a autonomização da área, em 1993, quando esta foi representada por uma cientista social (profa. Cecília Minayo, da Ensp), todos os representantes de área subseqüentes são epidemiólogos ou originários da Epidemiologia, e que as comissóes de avaliação de Saúde Coletiva são compostas majoritariamente por epidemiólogos (gráfico 11). O mesmo ocorre com o CNPq onde os comitês assessores da área são compostos majoritariamente por epidemiólogos (gráfico 12). Atualmente, os epidemiólogos reinam com tranqüilidade, dando as cartas nas agências, tanto na Capes quanto no CNPq.

Gráfico 11: Distribuição dos membros das Comissões de Avaliação Saúde Coletiva. Capes (1998-2005)

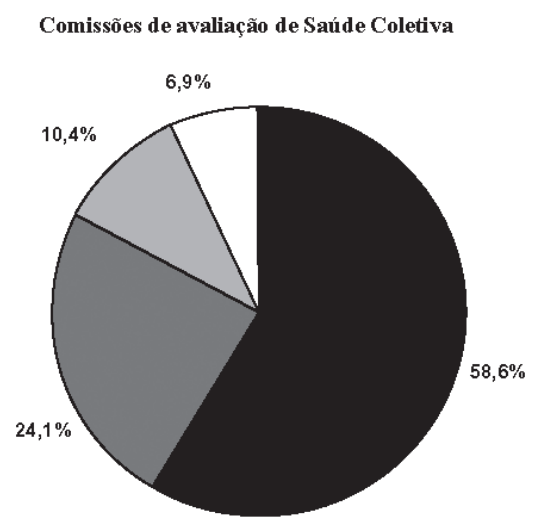

Epidemiologia $\square$ Ciências Humanas $\square$ Política e Planejamento $\square$ Diversas

Fonte: Capes. 


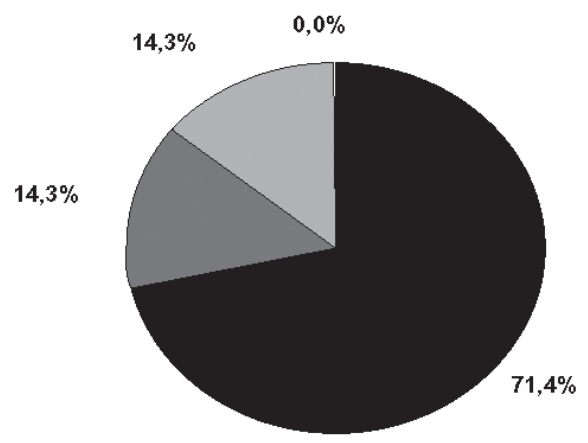

\section{- Epidemiologia $\square$ Ciências Humanas $\quad \square$ Política e Planejamento $\square$ Diversas}

* Os dados disponíveis para o CNPq restringem-se aos anos de 2006 e 2007. Fonte: CNPq.

Assim, não é de se estranhar que os epidemiólogos prefiram autonomizar sua própria área (e atingir imediatamente, imaginam eles, o conceito 7) do que alterar os critérios de avaliação - o que, nestas circunstâncias, constituiria de fato um movimento antinatural, ou seja, contra a natureza dessa área. Mas, em verdade, os epidemiólogos são apenas em parte responsáveis por essa situação, porque quem dá realmente as cartas é o núcleo duro da medicina instalado na Grande Área da Saúde, onde os epidemiólogos são dominados e, portanto, sem condições de impor alterações que, como vimos, aliás, não lhes interessam. Por outro lado, alguns cientistas sociais em posição desconfortável na Saúde Coletiva, quando não desenvolvem uma luta fratricida por hegemonia com seus pares da área, atuam no sentido de buscarem reconhecimento em suas áreas de origem. E isto dificulta a montagem de uma estratégia política coesa que tenha como referência a área da Saúde Coletiva como um todo.

O Professor Aluísio Barros, no artigo citado (BARROS, 2006), até pela posição que ocupa, como coordenador da área de Saúde Coletiva na Capes, mostra ser um profundo conhecedor de todas as mazelas e dificuldades que cercam a classificação 
dos periódicos, já criticados em vários artigos e documentos (KERR-PONTES et al., 2005; CAPONI; REBELO, 2005; GUIMARÃES, 2007). Mas em lugar de propor caminhos alternativos, acaba por concluir:

ainda que se possa questionar aspectos específicos do processo de avaliação, é impossível afirmar que ele possa ter qualquer efeito deletério. Numa situação de baixa competitividade como a da universidade brasileira, o processo de avaliação parece funcionar como propulsor. Papel que em países como os Estados Unidos e Inglaterra acaba sendo desempenhado pela disputa de posições nas universidades e subseqüente manutenção, já que parcela majoritária dos docentes é contratada por períodos determinados e paga com dinheiro de convênios e projetos de pesquisa (soft money). (BARROS, 2006, p. 48).

\section{Conclusão}

Tudo indica, pois, que nenhuma mudança a curto prazo possa ser esperada das agências. E que o caminho que nos resta é nos conformarmos, já que a batalha pela competitividade neste momento, parece de antemão perdida para as ciências humanas e sociais.

Acho difícil encontrar uma saída para esse imbróglio, que teve início como um processo necessário e bem intencionado, e terminou da forma que conhecemos hoje. As propostas de autonomização, seja da epidemiologia, seja das ciências humanas, podem funcionar para efeitos de avaliação, mas trazem o risco de desfigurar a própria área da Saúde Coletiva e de esvaziá-la de sua riqueza maior: a multidisciplinaridade. Negociaçôes do tipo "cada um cede um pouco", como vêm sendo propostas, não levam em conta que os que têm muito podem perder um pouco, mas os que já têm pouco arriscam ficar e certamente ficarão, com cada vez menos ou quase nada.

Minha proposta, sem desprezar negociações imediatas certamente paliativas, é mais radical. Não tenho dúvidas de que a avaliação de nossa área, tal como se apresenta hoje, se transformou num processo deletério que se agrava e tende a se agravar ainda mais, quanto mais tentamos ajustá-lo sem críticas ao padrão médico e internacional. No meu entender, é o próprio sistema de avaliação da área que precisa ser alterado, em função da realidade da área e da saúde em nosso país, e não apenas de parâmetros médicos e internacionais ditados por alguns países.

A avaliação é necessária e desejável? Claro que sim. Como também são desejáveis a unidade e a democratização da área. E acredito que dispomos de criatividade 
suficiente para elaborar propostas alternativas. Mais difícil, sem dúvida, será agregar vontade política para isso, pois o problema é eminentemente político, ou como preferem alguns, um problema de poder e como tal deve ser abordado e encaminhado.

Termino deixando para reflexão uma frase retirada do artigo de um cientista da área da saúde sobre o drama que vivemos:

O que começou como a medida de um avaliador externo se tornou nosso (próprio) objetivo. Embora existam boas razões para publicar artigos onde eles provavelmente serão mais lidos, quando damos prioridade aos periódicos em detrimento da ciência, nos tornamos filisteus em nosso próprio mundo.

Esta frase não é de um cientista social ressentido nem de um artigo publicado num periódico Qualis C. Mas foi retirada do artigo de Peter Lawrence (2003), do laboratório MCR de Biologia Molecular da Universidade de Cambridge, ex-editor da revista Cell, publicado na Nature. Ela nos mostra que temos aliados, e entre os mais poderosos. E também nos alerta, e não posso evitar minha mineiridade, "que enquanto estamos indo com o fubá, eles já estão voltando com a farinha".

\section{Referências}

BOURDIEU, Pierre. Entrevista a Maria Andréa Loyola. Rio de Janeiro, Eduerj, 2002. 98p. (Coleção Pensamento Contemporâneo, 1).

BARRADAS BARATA, Rita; GOLDBAUM, Moisés. Perfil dos pesquisadores com bolsa de produtividade em pesquisa do CNPq da área de saúde coletiva. Cadernos de Saúde Pública, Rio de Janeiro, v. 19, n. 6, p. 1863-1876, nov. /dez. 2003.

BARROS, Aluisio, J D. Produção científica em saúde coletiva: perfil dos periódicos e avaliação pela Capes. Revista de Saúde Pública, São Paulo, v. 40, p. 43-9, ago. 2006. (Número especial).

CAPONI, Sandra; REBELO, Fernanda. Sobre juízes e profissōes: a avaliação de um campo disciplinar complexo. PHYSIS: revista de saúde coletiva, Rio de Janeiro, v. 15, n. 1, p. 59-82, 2005.

DUARTE NUNES, Everardo. Pós-graduação em saúde coletiva no Brasil: histórico e perspectivas. PHYSIS: revista de saúde coletiva, Rio de Janeiro, v.15, n. 1, p.13-38, 2005.

GUIMARÃES, Reinaldo. Qualidade, impacto e citação: uma relação obscura RADIS, Rio de Janeiro, v. 55, p.19, mar. 2007.

LAWRENCE, Peter. The politics of publication. NATURE, v. 422, p. 259-261, march. 2003.

LUZ, Madel Therezinha. Prometeu acorrentado: análise sociológica da categoria produtividade e as condiçôes atuais da vida acadêmica, PHYSIS: revista de saúde coletiva, Rio de Janeiro, v. 15, n.1, p. 39-57, 2005. 
O PERFIL do curso "A": critérios a serem adotados pelas comissões de consultores da CAPES na avaliação dos cursos de mestrado e doutorado. INFOCAPES: boletim informativo, Brasília, DF, v. 2, n. 3, p. 13-21, jul. /set. 1994.

UNIVERSIDADE DE SÃO PAULO. Faculdade de Saúde Pública. Consideraçōes sobre a qualificação de livros no âmbito da área de saúde coletiva. São Paulo, SP, 2007, p.1-7, mimeografado.

\section{Notas}

${ }^{1}$ Artigo apresentado em forma de palestra no IV Congresso Brasileiro de Ciências Sociais e Humanas em Saúde, realizado em Salvador, de 13 a 18 de julho de 2007.

${ }^{2}$ Por esta razão, ou seja, por terem como objeto basicamente o indivíduo e por serem majoritariamente médicos, os psicanalistas, ainda que sob muitos aspectos, possam ser alinhados aos cientistas sociais, ocupam posição especial no campo da saúde coletiva, que mereceria uma análise à parte. 


\section{ANEXO 1 - APÊNDICE METODOLÓGICO}

As áreas dos artigos foram determinadas a partir do currículo Lattes do autor principal, do resumo de cada artigo e de suas palavras-chave. Foram classificados como:

Epidemiologia: estudos epidemiológicos em geral: fármaco-epidemiologia, epidemiologia psiquiátrica, vigilância epidemiológica, epidemiologia quantitativa,etc.

Ciências Humanas: história, ciências sociais, filosofia, educação, psicologia e algumas do serviço social (outras do serviço social entraram em Política e Planejamento).

Política e Planejamento: avaliação de programas/serviços de saúde, atendimento, políticas públicas de saúde, avaliações institucionais.

Diversos: A) artigos das "ciências duras" que não contavam com palavras-chave da área da epidemiologia e que não contavam com primeiros autores com formação em epidemiologia (por ex., da área de biologia, dermatologia, química, odontologia, farmácia, ciências médicas, fisioterapia e outras).

B) artigos que tinham muitas palavras-chave que tornavam a classificação em epidemiologia, políticas de saúde/planejamento e ciências humanas arbitrária. Isso aconteceu principalmente com artigos híbridos entre a "política planejamento/ ciências humanas".

Observação geral: $\mathrm{Na}$ análise dos Currículos Lattes (para definir os perfis das comissões, dos presidentes e dos conselhos editoriais), alguns pesquisadores apresentaram formação que não permitia uma classificação clara. Por exemplo: Doutorado em Saúde Pública (sem especificação de ênfase em). Nestes casos, foi utilizada a seção do Currículo Lattes Áreas de atuação, na qual os autores especificam melhor suas áreas de trabalho (epidemiologia, política e planejamento, humanas, diversos).

Agradecimento: O levantamento dos dados e a elaboração dos gráficos foram realizados por Eduardo Ribas De Biase Guimarães, mestrando do IMS-UERJ. 


\section{The Social Sciences Saga in the Field of Collective Health: Keys for Reflection}

The contribution of the social sciences, with theories and methods, has benn since the 1970's essential to the development and consolidation of the field known to health studies as collective health. Despite their major role, the social sciences have always occupied a lesser place in this field, which was dominated, since the 1970's and the 1980's, by health planning and, later, in the 1990's, by epidemiology. The preponderance of epidemiology occurred just when it was recognized by Capes (High-Level Personnel Perfectioning Coordination) as an autonomous field of study; a greater balance between different disciplines that are part of the collective health area was expected. This paper raises questions concerning the situation of the social sciences in this field, and in relation to the execution of incentives policy of national agencies such as Capes and CNPq (National Council for Scientific Research). The influence of a cost-benefit logic of predominantly economicist and quantitativist character, applied by the agencies in the concession of resources, interferes in the production as well as the circulation of knowledge, with severe losses for the social sciences. Surpassing this situation is one of the present challenges for social sciences and, in particular, to the collective health field.

> Key words: Health field; social sciences and health; collective health periodicals; productivity and productivism in collective health; supporting agencies and collective health. 